\title{
LOAD-FREQUENCY OPTIMIZATION WITH HEURISTIC TECHNIQUES IN A AUTONOMOUS HYBRID AC MICROGRID
}

\author{
Dursun ÖZTÜRK ${ }^{* 1}$, Hakan ÇELIK ${ }^{2}$, Mahmut Temel ÖZDEMİ ${ }^{3}$ \\ ${ }^{* 1}$ Department of Electrical and Electronics Engineering, Faculty of Engineering and Architecture, \\ Bingol University, Bingol, Turkey \\ ${ }^{2}$ Department of Mechatronics Engineering, Faculty of Engineering, Firat University, Elazig, Turkey \\ ${ }^{3}$ Department of Electrical and Electronics Engineering, Faculty of Engineering, Firat University, \\ Elazig, Turkey \\ *E-mail: dozturk@bingol.edu.tr
}

The main problem that arises during the operation of all these power systems is load-frequency control. Load-frequency control is a common problem of power systems that are connected to an interconnected system. Variations in the frequency in the interconnected power systems can lead to large-scale and serious instability problems. And in microgrids, loadfrequency control is of great importance in order to provide active power balancing, especially when the microgrids are connected to the main grid. In this study, AC microgrid structures and their basic control cycles are examined. A sample autonomous hybrid $A C$ microgrid structure was modeled in the MATLAB environment and an autonomous hybrid AC microgrid system isolated from the main grid was considered to be the case study. In this case, the controller gains are determined according to the Optic Inspired Optimization, Bacterial Swarm Optimization, Artificial Bee Colony Optimization, Ant Colony Optimization, Grey Wolf Colony Optimization algorithms, costing with the ISE performance criteria which are commonly recognized in the literature. The controller gains determined by optimization were simulated for time domain responses in the generated model and the results were analyzed.

Key words: Autonomous hybrid ac microgrid, load-frequency control, optics inspired optimization, bacterial swarm optimization, artificial bee colony optimization, ant colony optimization, grey wolf colony optimization

\section{Introduction}

Microgrids are new generation energy production systems that can be controlled independently and include distributed energy resources (DER), and can operate on grid or off grid, established in the vicinity of the consumer [1]. DERs in the microgrid-system are rather cleaner, more sustainable and environment-friendly renewable sources $[2,3]$. These are energy sources that produce and store 
electrical energy in the low voltage or medium voltage range. While the electricity production systems such as hydroelectric, wind, solar, cogeneration, which produce less than $30 \mathrm{MW}$ of energy, generate distributed production; the systems such as battery, flywheel and ultra-capacitor store the distributed energy [1]. These distributed storage systems perform storage operations with various energy transformations. These storage units in DERs have increasing effect on the overall performance of the system. They cover a significant gap in the system to meet the short-term but high energy needs and they allow the system to function more stable [4-8].

Attraction of large-scale energy production systems have diminished due to the changes in the energy sector; the daily change in pricing due to the changes in the costs, irregularities in nature, and the environmental effects. As a result of this, producing electrical energy at locations that are electrically close to the consumption centers will bring many advantages. Such production systems have emerged as a supplementary element to the overall sustainability of the power system. At the same time, with their specialty of feeding the region in case of isolation in the system, they offer an appropriate solution to the region where the DERs are located [9]. Hence, the hybrid energy generation systems created by DERs have given a new dimension to the overall planning and operations of the system. However, there are difficulties in integrating these systems into the main grid. In this context, their effects on the system when it is isolated and connected to the main grid need to be researched carefully. DERs should be able to hold the voltage and frequency of the hybrid system steady in case of isolation, opposed to the main grid -on grid situation. For this, the active and reactive power demanded by the loads must be met on time and in sufficient quantity. The isolated working condition is much more difficult and requires attention than the grid-connected situation[10].

The first study on load-frequency control, which is a topic of automatic production control, was carried out by Cohn (1967) [11]. From that date on, it has been a crucial subject for researchers, considering its area of effect and the economic losses it causes. These investigations are now focused on hybrid systems[12]. Lee and Wang (2008) examined the effects of the different components of a hybrid system on the performance of the system [13]. Das et al. (2012) have investigated the performance of a solar thermal hybrid system in their study [14]. Wang et al. (2008) studied a hybrid system with a DC connection line and performed dynamic analysis [15]. Senjyu et al. (2005) examined the effects of the wind production system on the hybrid system with different scenarios and the effects of the electrolysis and fuel cell on the system [16]. Many researchers have investigated the effects of energy storage techniques on the hybrid system [14, 16-21].

Optimization techniques are widely used to solve difficult and complex engineering problems. In this context, the complexity of power systems increases day by day and it becomes increasingly difficult to control. For this reason, intelligent optimization methods should be used to check and optimally operate the system. The changes in DERs' primary energy sources (seasonal changes) cause uncertainties in production, moreover, when it comes together with the uncertainties in consumers, a difficult and important optimization problem arises. For this reason, researchers have proposed solutions using various optimization methods.

With this introduction, a hybrid power system model and load-frequency control are discussed and introduced in the study. In the method section, information on the heuristic optimization methods used and the three scenarios for the use in the prepared power system are presented. In the findings 
section, the system is optimized for 3 different scenarios and time domain simulations of the system are made according to the controller gains obtained and these results are given. And in the conclusion section, the results obtained are discussed.

\section{Autonomous Hybrid Microgrid And Load-Frequency Control}

In power systems, the voltage and frequency control is related to system's active and reactive power balance [22-26]. The automatic control method applied to electrical power systems in order to reconstruct the active power balance which is distorted as a result of the load change in the system and to minimize the error of the system frequency deviating from the nominal value is called loadfrequency control $[21,27,28]$. The load-frequency cycles for a microgrid are presented in Figure 1.

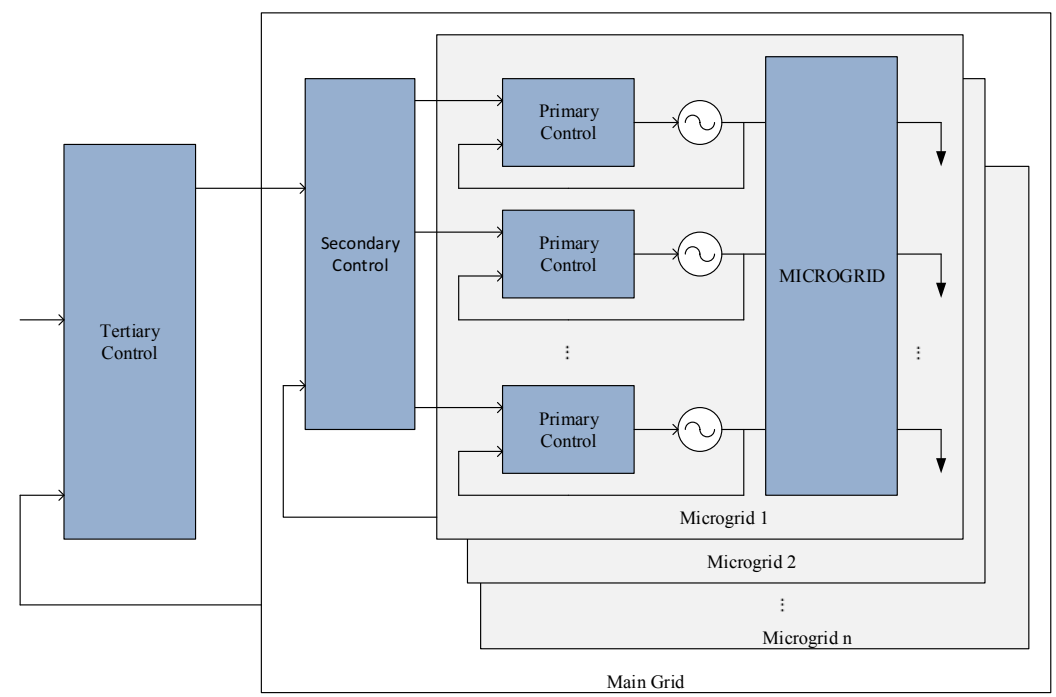

Figure 1. Hierarchical Frequency Control Scheme

For a steady-state power system it is essential that the frequency remains constant. And a constant frequency is only possible with power balance. The term power balance refers to the sum of the generated active power to be equal to the sum of the system losses, the system active loads, and the power transmitted through the connection lines. If this equality is not achieved, meaning that, when there is an imbalance between the generated power and the consumed power, the frequency value also increases or decreases. If the energy produced is higher, the frequency value will increase and if the energy consumed is higher, the frequency value will decrease. In addition, power fluctuations in the connection lines between power systems connected to an interconnected system also affect the frequency negatively. Such changes can cause damage to frequency-dependent devices, even the failure of the entire power system.

In summary, the load-frequency control applied to a power system has two main tasks. The first is to set the generator's active power according to the demand and keep the frequency value constant on this count. A turbine shaft is rotated by mechanical force, which in turn turns the generator rotor, which is connected to the shaft that provides inducing voltage in the generator stator. The rotational 
speed of the turbine shaft rotated by the mechanical energy determines the frequency value of this electric energy. In other words, the system frequency is also controlled by adjusting the energy produced in the turbine. The second task of load-frequency control is to ensure a balanced production by distributing the demanded load among the interconnected power systems in order to reduce operating costs.

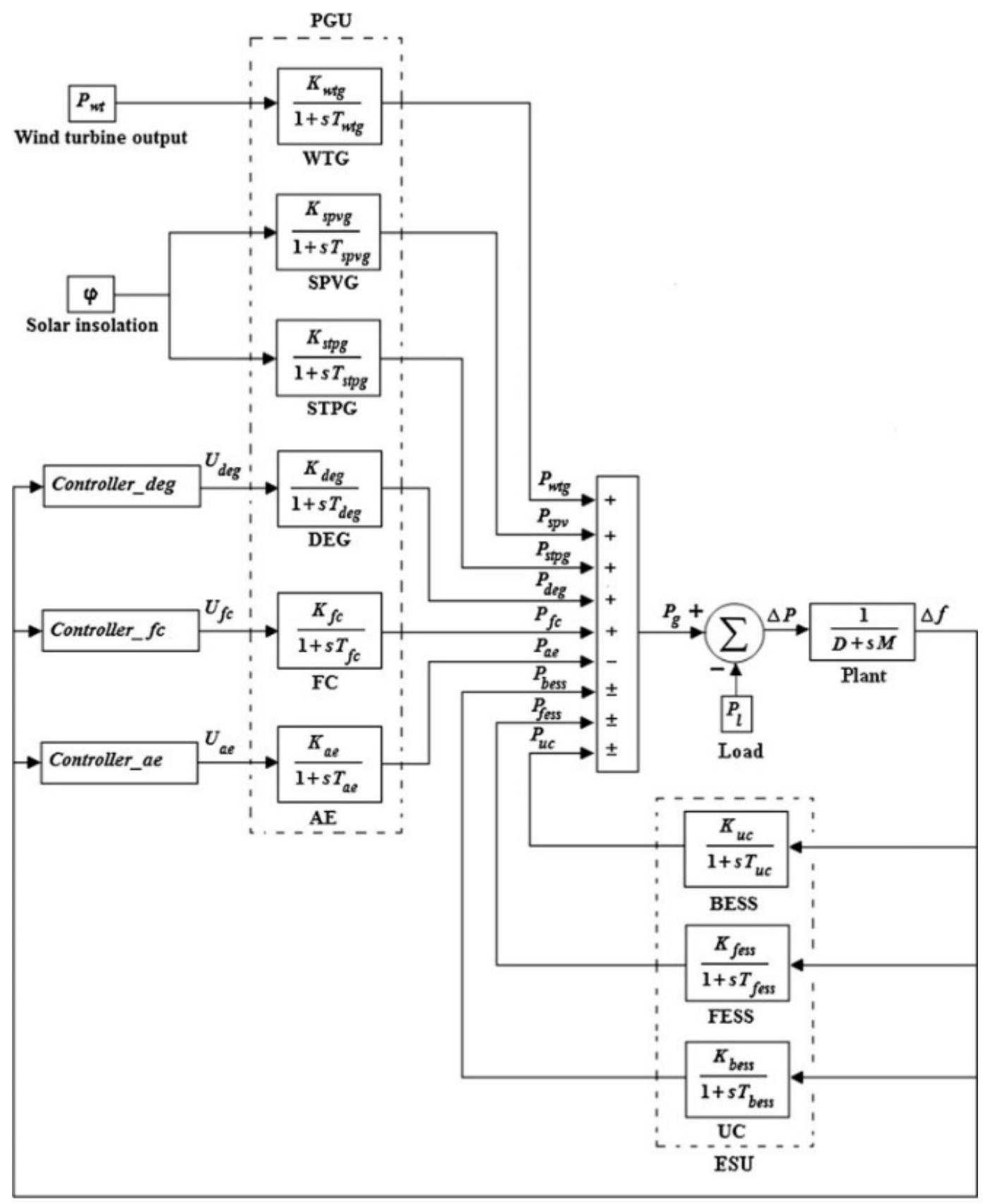

Figure 2. Generalized block diagram of the studied hybrid power system[29]

Figure 2 shows the MATLAB model of the microgrid hybrid power system and the energy production equations for each power unit. The system parameters are taken from Shankar and Mukherjee [29]. The wind turbine generator (WTG), solar photovoltaic generator (SPVG), solar 
thermal power generator (STPG), diesel energy generator (DEG), battery energy storage system (BESS), ultra capacitor (UC), fuel cells (FC), flywheel energy storage system (FESS) and aqua electrolyzer (AE) are the power units that are in the hybrid power system model.

\section{Heuristic Optimization}

In this section; the optimization techniques that will find optimal value of controller gains of the controlled production sources in the hybrid AC microgrid model will be presented. Following that, the descriptions of the three different scenarios were made.

Optimization is determining the most appropriate solution method to solve a problem. Today, there are many methods developed for optimization studies. One of these is the heuristic method. With the heuristic methods, appropriate solutions are developed in reasonable time for large-scale optimization problems. Heuristic methods are divided into sub-method techniques developed for different problems. These are; biology, physics, colony, social, music and chemistry based intuitive method techniques. The optimization technique that we use in our work is colony based. The colony based algorithms were developed by being inspired from the intelligent behaviors of the colonies [30].

\subsection{Artificial Bee Colony Optimization Algorithm}

The Artificial Bee Colony ( $\mathrm{ABC}$ ) algorithm is one of the recently developed colony intelligence based optimization techniques. It's not being complex, not needing for a large number of control parameters, and being easy to implement have made the $\mathrm{ABC}$ algorithm, which is suggested by Karaboğa, considerably popular [31]. Besides its superior aspects, its being insufficient in responding the needs of the local research mechanism among the adjoining solutions, might be called as one of the disadvantages of the ABC algorithm [32-34].

In the $\mathrm{ABC}$ algorithm, optimization is performed by modeling the methods of bees'nutrient finding methods. According to the algorithm, there are worker bees, observer bees and explorer bees in artificial colony. While the worker bees hold the food sources, the watchers observe the worker bees to select the food sources, and the explorers make random searches [31]. At the beginning of the algorithm, food resources are created in the first step. Each of the worker bees select a food source and collect nectar and return to their hives. The workers inform the observers about the distance, direction and quality of the source they have found with various dances they perform in the field of dance inside the hive [31]. Observer bees choose food sources with certain possibilities in the light of this information and collect nectar from the source. Workers, who finish food resources with iterations, turn into explorer bees. The explorers also reach to any source of food and continue collecting nectar. Thus a cycle is established and the cycle continues until the desired conditions are met.

The basic steps of the $\mathrm{ABC}$ algorithm are given below:

1: Identify food sources

2: Iterate

3: Send worker bees to food sources

4: Do estimated calculations for food sources

5: Send scout bees to sources identified by estimated calculations 
6: Send explorer bees to find other food sources

7: Keep the best food source until that time in memory

8: white (Has the condition for termination met?)

\subsection{Bacterial Swarm Optimization Algorithm}

The Bacterial Swarm Optimization Algorithm (BSOA) was developed being inspired from the ability of the Escherichia coli (E. coli) bacteria to search and find nutrients. Bacteria are simple structured creatures. Nevertheless, they meet their nutritional needs by reasonably using all their means. Moreover, modeling them is much easier than their complex life forms. This species of bacteria living in the intestines of many living things around the world, make chemical secretions when they find nutrients. Other bacteria are stimulated by the substance they secrete and they are allowed to move towards the food. If the nutrient density is high there, the bacteria move in groups as they clamp [21, 35-37].

BSO basically consists of 4 steps;

Step 1: Create the population.

Step 2: Evaluate the individuals according to the assessment function.

Step 3: Three loops for optimization:

Inner Cycle: Chemotactic event

Middle Cycle: Reproduction event

External Cycle: Elimination-scattering event

Step 4: Solve the code of the optimal individual to determine the final solution.

\subsection{Ant Colony Optimization Algorithm}

ACO was developed in 1991 by Dorigo et al., inspired by the behaviors of real ant colonies. Ant Colony Optimization (ACO) is a population-based approach that is often used in optimization problems [38, 39].

Real ants have the intuition to find the shortest path between food sources and their nests. In the first stage, ants are dispersed with equal possibilities to alternative routes, and after a while they begin to gather on the shortest route. Since the visual senses of the ants do not develop, they take advantage of the chemical communication they have developed between them during their exploration of this short route. They use a chemical substance called pheromone, which they secrete from their bodies, for this communication. Pheromone traces are updated by the ants and they represent certain information. The excess of pheromone concentration in a path increases the possibility of that route's being preferred. And in the algorithm, artificial ants investigate the shortest route on the model, which is prepared considering real distances. The tracks of the pheromones on the roads are also artificially updated in proportion to the transit frequency of the ants. Below are the basic steps of a simple ACO algorithm.

Start

Producing paths for all artificial ants

Calculation of the length of all artificial paths

Updating the amount of pheromone substance on artificial paths 
Keeping the shortest artificial path that is found until now in memory

Achievement of qualification criteria

End

\subsection{Grey Wolf Colony Optimization Algorithm}

The Gray Wolf Optimizer (GWO) imitates the leadership hierarchy and hunting techniques of gray wolfs $[40,41]$. There are four types of grey wolfs according to the algorithm: $\alpha, \beta, \delta, \omega$. These are used to simulate their hierarchy of leadership. $\alpha$ is the leader and decision maker. $\beta$ and $\delta$ help $\alpha$ in the decision making phase. The remaining gray wolfs $(\omega)$ follow the other gray wolfs. The hunting behavior of the gray wolf colony corresponds to the stages of the optimization. Hunting behaviors also consist of three basic steps: Searching the hunt, sieging the hunt and attacking the hunt.

When we pattern the social hierarchy of the gray wolfs mathematically in the optimization; we can recommend $\alpha$ as the most appropriate solution, and the second and third most appropriate solutions are $\beta$ and $\delta$, respectively. $\omega$ is the solution following the other three solutions.

The main advantages of the grey wolf colony algorithm are; it provides the opportunity of easy application in the simple cases, it requires less memory than other techniques, it has only two basic parameters ( $\mathrm{a}$ and $\mathrm{C}$ ), its convergence is faster and the number of its decision variables is very small $(\alpha, \beta$ ve $\delta)$.

\subsection{Optics Inspired Optimization Algorithm}

OIO algorithm is a physics-based heuristic algorithm introduced by Ali Husseinzadeh Kashan in 2013 [42, 43]. It was developed by being inspired from optics, which is one of the laws of physics. OIO is an algorithm assuming that there are series of artificial light points (points at $\mathrm{Rn}+1$ matching at $\mathrm{Rn}$ are potential solutions to the problem) of an artificial mirror reflecting the image. Each bump is accepting as a convex reflecting surface and each concave is considered as a concave reflecting surface. In this way, an artificial light coming from an artificial light point is reflect back from the function surface of a part of convex or convey surface. Artificial image point (like a new solution in the search area at $\mathrm{Rn}+1$ matching at $\mathrm{Rn}$ ) is either straight (in the direction of position of light point in the search space) or reverse (outward from position of light point in the search space).

\section{Scenarios}

The hybrid power system model in the case of Scenario 1 includes WTG, STPG, DEG, FC, AE and BESS units and simulations were performed for $\mathrm{t}=120 \mathrm{~s}$. As shown in Table 1, Pwtg and Pstpg values were kept at $0.5 \mathrm{pu}$ and $0.36 \mathrm{pu}$ respectively for $\mathrm{t}=0-40 \mathrm{~s}$. After $40 \mathrm{~s}$, these values were reduced to $0.4 \mathrm{pu}$ and $0.18 \mathrm{pu}$ respectively. The PL value was maintained at $1.0 \mathrm{pu}$ for $80 \mathrm{~s}$ and increased to $1.1 \mathrm{pu}$ after $80 \mathrm{~s}$.

Table 1. Details of the different studied scenarios of hybrid power system

\begin{tabular}{|l|l|l|l|}
\hline Scenario & Elements of studied hybrid power system & $\begin{array}{l}\text { Simulation } \\
\text { time (s) }\end{array}$ & Range \\
\hline
\end{tabular}




\begin{tabular}{|c|c|c|c|}
\hline 1 & $\begin{array}{l}\text { Power Generating Units: WTG, STPG, DEG, FC, AE } \\
\text { Energy storage units: BESS } \\
\text { Load demand: } \mathrm{P}_{L}\end{array}$ & 120 & $\begin{array}{c}P_{w t g}=\left\{\begin{array}{c}0.5 p . u . \text { for } 0<t<40 s \\
0.4 . p . u . \text { for } t \geq 40 s\end{array}\right\} \\
P_{\text {stpg }}=\left\{\begin{array}{c}0.36 \text { p.u. for } 0<t<40 s \\
0.18 \text { p.u. for } t \geq 40 s\end{array}\right\} \\
P_{L}=\left\{\begin{array}{c}1.0 \text { p.u.for } 0<t<80 s \\
1.1 \text { p.u.for } t \geq 80 s\end{array}\right\}\end{array}$ \\
\hline 2 & $\begin{array}{l}\text { Power Generating Units: WTG, SPVG, DEG, FC, AE } \\
\text { Energy storage units: BESS, FESS } \\
\text { Load demand: } \mathrm{P}_{L}\end{array}$ & 120 & $\begin{array}{c}P_{w t g}=\left\{\begin{array}{c}0.5 p . u . \text { for } 0<t<40 s \\
0.4 . p . u . \text { for } t \geq 40 s\end{array}\right\} \\
P_{\text {spvg }}=\left\{\begin{array}{c}0.2 \text { p.u. for } 0<t<40 s \\
0.1 \text { p.u. for } t \geq 40 s\end{array}\right\} \\
P_{L}=\left\{\begin{array}{c}1.0 \text { p.u. for } 0<t<80 s \\
1.3 \text { p.u.for } t \geq 80 s\end{array}\right\}\end{array}$ \\
\hline 3 & $\begin{array}{l}\text { Power Generating Units: WTG, SPVG, DEG, FC, AE } \\
\text { Energy storage units BESS, UC } \\
\text { Load demand: } \mathrm{P}_{L}\end{array}$ & 120 & $\begin{array}{c}P_{w t g}=\left\{\begin{array}{c}0.5 p . u . \text { for } 0<t<40 s \\
0.4 . p . u . \text { for } t \geq 40 s\end{array}\right\} \\
P_{\text {spvg }}=\left\{\begin{array}{c}0.2 \text { p.u. for } 0<t<40 s \\
0.1 \text { p.u. for } t \geq 40 s\end{array}\right\} \\
P_{L}=\left\{\begin{array}{c}1.0 \text { p.u. for } 0<t<80 s \\
1.3 \text { p.u.for } t \geq 80 s\end{array}\right\}\end{array}$ \\
\hline
\end{tabular}

The hybrid power system model in the case of Scenario 2 contains WTG, SPVG, DEG, FC, AE, BESS, and FESS units and simulations were performed for $t=120 \mathrm{~s}$. As given in Table 1, Pwtg and Pspvg values were kept at $0.5 \mathrm{pu}$ and 0.2 pu respectively for $\mathrm{t}=0-40 \mathrm{~s}$. After $40 \mathrm{~s}$, these values were $0.4 \mathrm{pu}$ for both. The PL value was maintained at $1.0 \mathrm{pu}$ for $80 \mathrm{~s}$ and increased to $1.3 \mathrm{pu}$ after $80 \mathrm{~s}$.

The hybrid power system model in the case of Scenario 3 includes WTG, SPVG, DEG, FC, AE, BESS and UC units and simulations were conducted for $\mathrm{t}=120 \mathrm{~s}$. As given in Table 1, Pwtg and Pspvg values were kept at $0.5 \mathrm{pu}$ and $0.2 \mathrm{pu}$ respectively for $\mathrm{t}=0-40 \mathrm{~s}$. After $40 \mathrm{~s}$, these values were increased to $0.4 \mathrm{pu}$ and $0.1 \mathrm{pu}$ respectively. The PL value was maintained at $1.0 \mathrm{pu}$ for $80 \mathrm{~s}$ and increased to $1.3 \mathrm{pu}$ after $80 \mathrm{~s}$.

\section{Simulation Results}

The controller gains determined as a result of the optimizations made for Scenario 1 are presented in Table 2. The cost values that the methods used in optimization have found as lowest are given as performance indexes. In the Table, the results of the study of Shankar and Mukherjee according to TLBOA and QOHSA methods were also added. In the optimization, taking the applicability into account, controller gains were limited to 20 . 


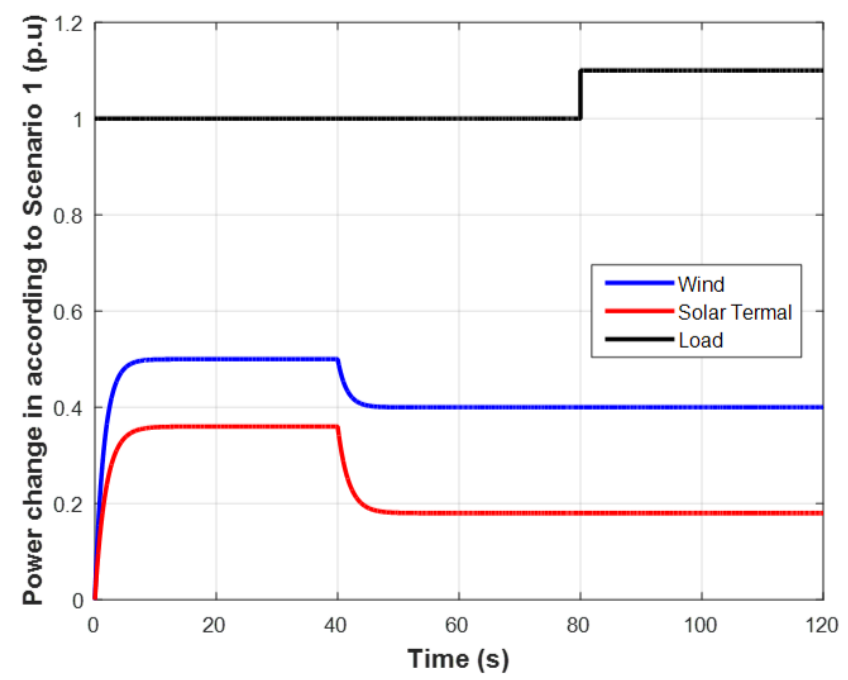

Figure 3. Pertaining to Scenario 1, variation of load demand, power generated from WTG and power generated from STPG

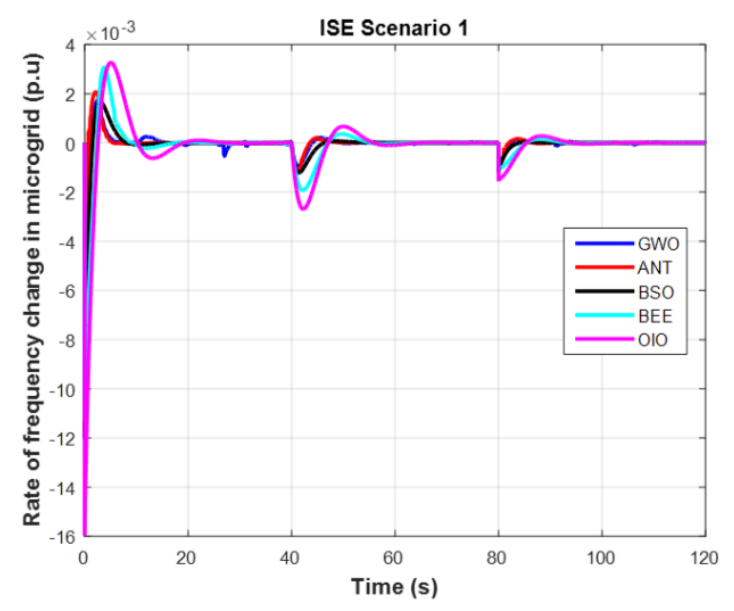

Figure 4. Frequency deviation of according to Scenario 1

Table 2. Optimized controller gains and cost values toScenario 1

\begin{tabular}{|c|c|c|c|c|c|c|c|c|c|c|}
\hline & \multicolumn{3}{|c|}{ DEG Controller } & \multicolumn{3}{|c|}{ FC Controller } & \multicolumn{3}{|c|}{ AE Controller } & \multirow{2}{*}{ Cost value } \\
\hline & $\boldsymbol{K}_{p}$ & $\boldsymbol{K}_{i}$ & $\boldsymbol{K}_{d}$ & $K_{p}$ & $\boldsymbol{K}_{i}$ & $\boldsymbol{K}_{d}$ & $\boldsymbol{K}_{p}$ & $\boldsymbol{K}_{i}$ & $K_{d}$ & \\
\hline OIO & 15.388 & 4.878 & 19.834 & 0.690 & 1.739 & 8.726 & 11.827 & 5.920 & 14.717 & 0.00021917 \\
\hline ABC & 19.941 & 11.963 & 19.892 & 0.334 & 0.412 & 17.46 & 0.089 & 17.209 & 11.78 & 0.000109 \\
\hline GWO & 8.402 & 17.944 & 18.99 & 19.743 & 5.998 & 19.69 & 2.431 & 3.618 & 19.422 & 0.00004689 \\
\hline ANT & 12.754 & 11.557 & 15.635 & 18.498 & 14.664 & 18.626 & 0.703 & 0.749 & 17.365 & 0.00005243 \\
\hline BSO & 18.786 & 7.246 & 13.25 & 17.493 & 5.624 & 19.956 & 7.375 & 9.97 & 17.32 & 0.00005841 \\
\hline TLBOA & 81.423 & 25.639 & 68.226 & 3.112 & 0.758 & 1.711 & 0.0628 & 0.0805 & 0.0647 & 0.0105 \\
\hline QOHSA & 92.477 & 38.212 & 94.795 & 4.496 & 1.422 & 4.564 & 0.0741 & 0.0435 & 0.0435 & 0.0067 \\
\hline
\end{tabular}

Figure 3 and Figure 4 show uncontrolled power changes in the system. In Table 2, time domain simulations based on the gains obtained are presented. According to the cost values in Table 2 , it is seen that the lowest cost are obtained with GWO. 


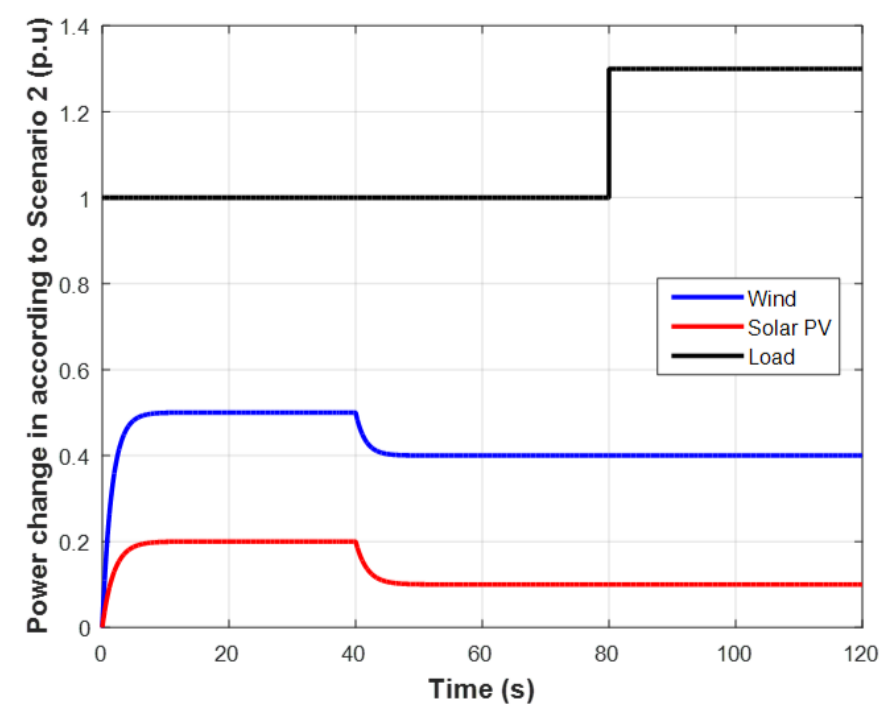

Figure 5. Pertaining to Scenario 2, variation of load demand, power generated from WTG and power generated from $P V$

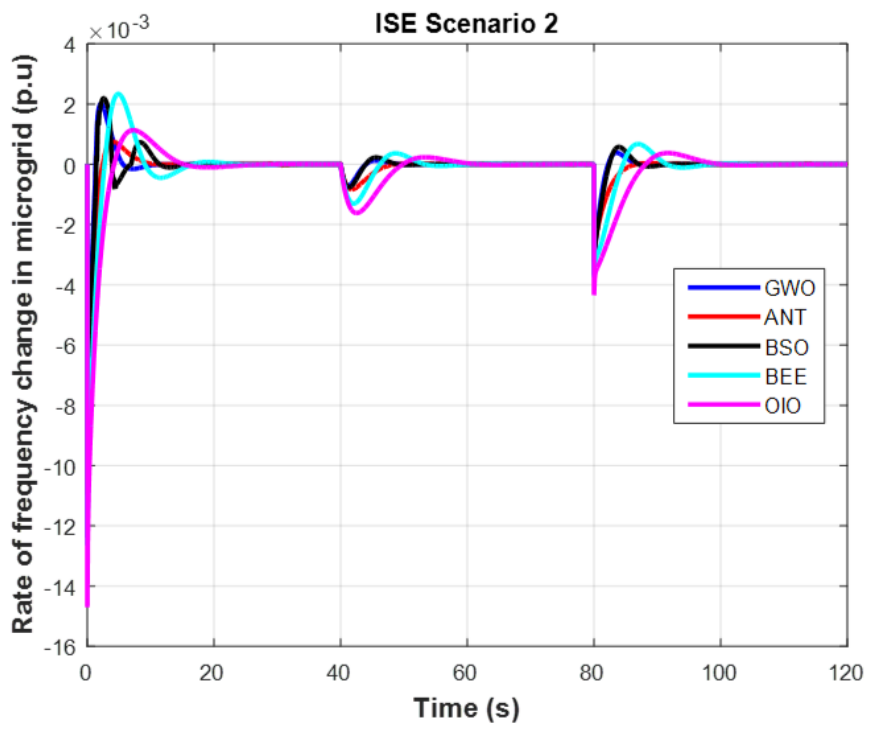

Figure 6. Frequency deviation of according to Scenario 2

Table 3. Parameters Specified for Scenario 2

\begin{tabular}{|c|c|c|c|c|c|c|c|c|c|c|}
\hline & \multicolumn{3}{|c|}{ DEG Controller } & \multicolumn{3}{|c|}{ FC Controller } & \multicolumn{3}{|c|}{ AE Controller } & \multirow{2}{*}{ Cost value } \\
\hline & $K_{p}$ & $\boldsymbol{K}_{i}$ & $\boldsymbol{K}_{d}$ & $\boldsymbol{K}_{p}$ & $\boldsymbol{K}_{i}$ & $\boldsymbol{K}_{d}$ & $K_{p}$ & $\boldsymbol{K}_{i}$ & $K_{d}$ & \\
\hline OIO & 16.987 & 3.170 & 19.045 & 1.889 & 1.653 & 10.820 & 18.948 & 12.158 & 16.087 & 0.00017300 \\
\hline $\mathbf{A B C}$ & 18.911 & 11.288 & 16.054 & 0.132 & 1.872 & 16.603 & 8.528 & 14.154 & 12.720 & 0.000125 \\
\hline GWO & 19.661 & 16.157 & 15.742 & 19.576 & 10.639 & 17.221 & 13.307 & 4.106 & 13.869 & 0.00005389 \\
\hline ANT & 17.137 & 5.353 & 18.844 & 17.872 & 4.284 & 19.896 & 5.974 & 1.811 & 0.176 & 0.00005276 \\
\hline BSO & 15.44 & 11.669 & 17.433 & 16.341 & 12.871 & 19.709 & 14.282 & 6.196 & 19.022 & 0.00005686 \\
\hline TLBOA & 80.981 & 69.623 & 98.41 & 0.146 & 0.077 & 0.469 & 0.0663 & 0.3820 & 0.447 & 0.0161 \\
\hline QOHSA & 90.779 & 48.378 & 96.81 & 0.461 & 0.051 & 0.572 & 0.3497 & 0.2532 & 0.266 & 0.0093 \\
\hline
\end{tabular}


Vol 2, Number 1, 2017

ISSN: 2548-0332

doi: 10.23884/IJESG.2017.2.1.01

Figure 5 and Figure 6 show uncontrolled power changes in the system. In Table 3, time domain simulations based on the gains obtained are presented. According to the cost values in Table 2, it is seen that the lowest cost are obtained with ANT.

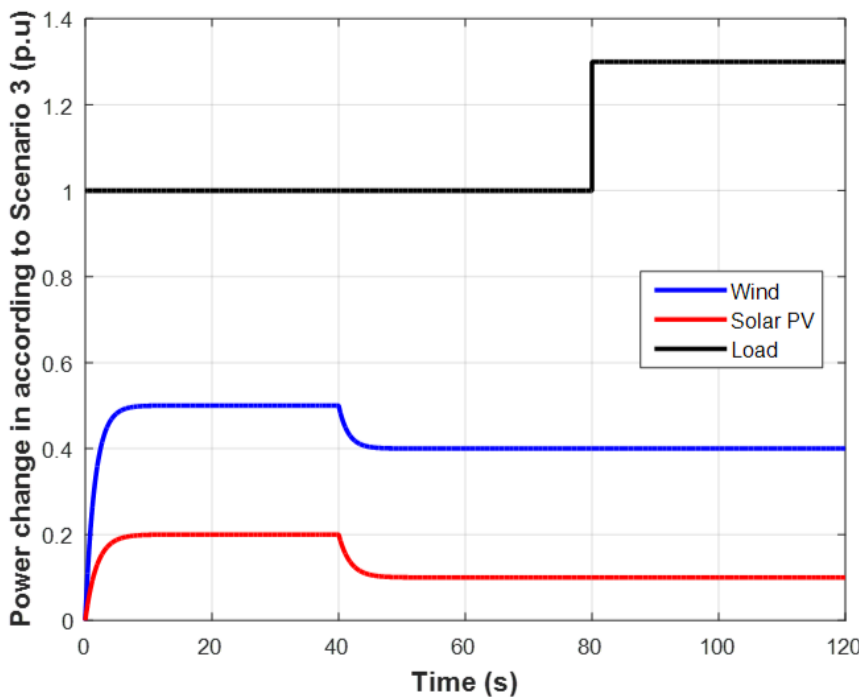

Figure 7. Pertaining to Scenario 3, variation of load demand, power generated from WTG and power generated from STPG

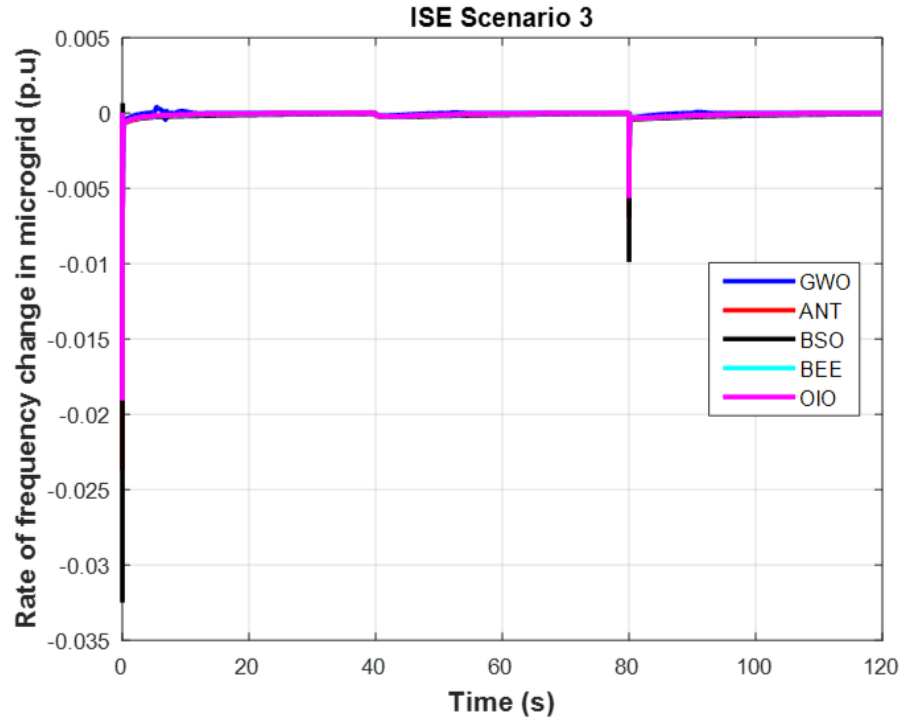

Figure 8. Frequency deviation of according to Scenario 3 
Table 4. Parameters Specified for Scenario 3

\begin{tabular}{|c|c|c|c|c|c|c|c|c|c|c|}
\hline & \multicolumn{3}{|c|}{ DEG Controller } & \multicolumn{3}{|c|}{ FC Controller } & \multicolumn{3}{|c|}{ AE Controller } & \multirow{2}{*}{ Cost value } \\
\hline & $K_{p}$ & $K_{i}$ & $K_{d}$ & $K_{p}$ & $K_{i}$ & $K_{d}$ & $\boldsymbol{K}_{p}$ & $K_{i}$ & $\boldsymbol{K}_{d}$ & \\
\hline OIO & 7.053 & 19.677 & 1.198 & 0.586 & 0.296 & 15.489 & 6.206 & 3.535 & 11.233 & 0.00001544 \\
\hline ABC & 12.095 & 15.186 & 18.593 & 19.337 & 13.149 & 7.101 & 1.522 & 1.264 & 17.315 & 0.00000814 \\
\hline GWO & 19.16 & 14.936 & 13.681 & 17.433 & 2.440 & 11.512 & 17.664 & 19.516 & 11.876 & 0.00001023 \\
\hline ANT & 0.341 & 0.167 & 14.934 & 1.431 & 11.407 & 0.095 & 2.820 & 5.575 & 2.598 & 0.00002095 \\
\hline BSO & 3.383 & 1.009 & 0.635 & 3.194 & 0.518 & 2.400 & 12.643 & 3.405 & 7.441 & 0.00003287 \\
\hline TLBOA & 45.222 & 41.040 & 27.260 & 29.57 & 22.89 & 40.67 & 0.0844 & 0.2225 & 0.151 & 0.0034 \\
\hline QOHSA & 50.684 & 40.022 & 46.023 & 37.68 & 23.63 & 50.35 & 0.2771 & 0.4395 & 0.243 & 0.0023 \\
\hline
\end{tabular}

Figure 7 and Figure 8 show uncontrolled power changes in the system. In Table 4, time domain simulations based on the gains obtained are presented. According to the cost values in Table 4 , it is seen that the lowest cost are obtained with ABC.

\section{Conclusion}

The concept of microgrid has emerged as the result of increasing economic and environmental problems in traditional power systems. The use of renewable energy sources in microgrids has rapidly been becoming widespread in the power industry, due to its ability to reduce global warming and remove environmental constraints.

Since microgrids mostly use renewable energy sources in electric power generation, production amounts are not steady and are constantly changing. Changes in power systems and uncertainties reveal the inadequacy of classical controllers in achieving proper performance throughout the system's operation. In order to prevent this situation, the optimal values of the controller gains must be determined.

In this study, the frequency stability of a microgrid, which is isolated from the maingrid containing different power generation and energy storage units, was examined using its simulations in time domain. The full dynamic model of this hybrid power system is derived by considering simplified first order transfer function models of each power generation and energy storage unit. The dynamic performance of the load-frequency control of the system model developed according to the three scenarios is examined; and the controller gains used in the model are optimized by costing various heuristic optimization methods according to the ISE performance criteria.

In this study, the same scenarios have been used, considering the system that Shankar and Mukherjee have used. By comparing the results obtained for each scenario, optimization methods, which have given the best results according to cost indices, have been determined. According to this cost index, the gray wolf colony optimization algorithm for scenario 1, the ant colony optimization algorithm for scenario 2 and the artificial bee colony optimization algorithm for scenario 3 were determined as the best methods. In this study, when the results obtained were compared with the results obtained by Shankar and Mukherjee according to the ISE cost index, even the highest cost 
value of the methods used in this study is found to be 60 times lower than the lowest cost value of the mentioned study.

\section{References}

[1] El-Khattam, W., et al., Distributed generation technologies, definitions and benefits 2004, 71, pp. 119-128

[2] Doolla, S., et al., Automatic generation control of an isolated small-hydro power plant. Electric Power Systems Research, 76, (2006), 9-10, pp. 889-896.

[3] Banerjee, A., et al., Intelligent fuzzy-based reactive power compensation of an isolated hybrid power system. International Journal of Electrical Power and Energy Systems, 57, (2014), pp. $164-177$.

[4] Aghamohammadi, M.R., et al., A new approach for optimal sizing of battery energy storage system for primary frequency control of islanded Microgrid. International Journal of Electrical Power \& Energy Systems, 54, (2014), pp. 325-333.

[5] Barsali, S., et al., Storage applications for Smartgrids. Electric Power Systems Research, 120, (2015), pp. 109-117.

[6] Hien, N.C., et al., Location and Sizing of Distributed Generation Units for Loadabilty Enhancement in Primary Feeder. IEEE Systems Journal, 7, (2013), 4, pp. 797-806.

[7] Lopes, J.A.P., et al., Integrating distributed generation into electric power systems: A review of drivers, challenges and opportunities. Electric Power Systems Research, 77, (2007), 9, pp. $1189-1203$.

[8] Sebastián, R., et al., Control and simulation of a flywheel energy storage for a wind diesel power system. International Journal of Electrical Power \& Energy Systems, 64, (2015), pp. 1049-1056.

[9] Zhao, J.H., et al., Flexible transmission network planning considering distributed generation impacts. IEEE Transactions on Power Systems, 26, (2011), 3, pp. 1434-1443.

[10] Loh, P.C., et al., Autonomous control of interlinking converter with energy storage in hybrid AC-DC microgrid. IEEE Transactions on Industry Applications, 49, (2013), 3, pp. 1374-1382.

[11] Cohn, N., Considerations in the Regulation of Interconnected Areas. IEEE Transactions on Power Apparatus and Systems, PAS-86, (1967), 12, pp. 1527-1538.

[12] Hatziargyriou, N., et al., Microgrids 2007, 5, pp. 78-94

[13] Lee, D.-J., et al., Small-Signal Stability Analysis of an Autonomous Hybrid Renewable Energy Power Generation/Energy Storage System Part I: Time-Domain Simulations. IEEE Transactions on Energy Conversion, 23, (2008), 1, pp. 311-320.

[14] Das, D.C., et al., GA based frequency controller for solar thermal-diesel-wind hybrid energy generation/energy storage system. International Journal of Electrical Power \& Energy Systems, 43, (2012), 1, pp. 262-279.

[15] Wang, L., et al., Analysis of a novel autonomous marine hybrid power generation/energy storage system with a high-voltage direct current link. Journal of Power Sources, 185, (2008), 2, pp. 1284-1292.

[16] Senjyu, T., et al., A Hybrid Power System Using Alternative Energy Facilities in Isolated Island. IEEE Transactions on Energy Conversion, 20, (2005), 2, pp. 406-414.

[17] Gao, L., et al., Power Enhancement of an Actively Controlled Battery/Ultracapacitor Hybrid. IEEE Transactions on Power Electronics, 20, (2005), 1, pp. 236-243.

[18] Aditya, S.K., et al., Application of battery energy storage system to load frequency control of an isolated power system. International Journal of Energy Research, 23, (1999), 3, pp. 247258.

[19] Kottick, D., et al., Battery Energy Storage for Frequency Regulation in an Island Power System. IEEE Transactions on Energy Conversion, 8, (1993), 3, pp. 455-459.

[20] Ray, P., et al., Small-Signal Analysis of Autonomous Hybrid Distributed Generation Systems in Presence of Ultracapacitor and Tie-Line Operation. Journal of Electrical Engineering, 61, (2010), 4. 
[21] Özdemir, M.T., et al., Tuning of Optimal Classical and Fractional Order PID Parameters for Automatic Generation Control Based on the Bacterial Swarm Optimization. In: IFACPapersOnLine. 2015, pp. 501-506.

[22] Koç, F., et al., The Effect of Derivative Gain to System Stability in Automatic Voltage Regulator Systems. In: International Engineering, Science and Education Conference (INESEC) (Editors: B. Gümüş et al.). Diyarbakır, 2016, pp. 829-836.

[23] Özdemir, M.T., et al., An experimental system for electrical and mechanical education: Micro hydro power plant prototype. Procedia-Social and Behavioral Sciences, 47, (2012), pp. 2114 2119.

[24] Özdemir, M.T., et al., Effects of High Voltage Direct Current Transmission Lines on Load Frequency Control in a Multi Area Power System. In: Güç Sistemleri Konferans1 2016. 2016, pp. 1-5.

[25] Nur, A., et al., Power Flow Study For a Microgrid By Using Matlab And Powerworld SimulatorSIMULATOR. International Journal of Energy and Smart Grid, 1, (2016), 1, pp. 14 21.

[26] Efe, S.B., Power Flow Analysis of A Distribution System Under Fault Conditions. International Journal of Energy and Smart Grid, 1, (2016), 1, pp. 22-27.

[27] Çelik, V., et al., The effects on stability region of the fractional-order PI controller for one-area time-delayed load--frequency control systems. Transactions of the Institute of Measurement and Control, (2016), pp. 142331216642839.

[28] Özdemir, M.T., et al., Load-Frequency Optimization with Heuristic Techniques in A Hybrid $A C$ Microgrid. In: International Engineering, Science and Education Conference (INESEC). 2016, pp. 837-845.

[29] Shankar, G., et al., Load frequency control of an autonomous hybrid power system by quasioppositional harmony search algorithm. International Journal of Electrical Power \& Energy Systems, 78, (2016), pp. 715-734.

[30] Akyol, S., et al., Güncel Sürü Zekası Optamizasyon Algoritmaları. Nevşehir Bilim ve Teknoloji Dergisi, 1, (2012), 1.

[31] Karaboga, D., et al., A comparative study of Artificial Bee Colony algorithm. Applied Mathematics and Computation, 214, (2009), 1, pp. 108-132.

[32] Zhu, G., et al., Gbest-guided artificial bee colony algorithm for numerical function optimization. Applied Mathematics and Computation, 217, (2010), 7, pp. 3166-3173.

[33] Li, G., et al., Development and investigation of efficient artificial bee colony algorithm for numerical function optimization. Applied Soft Computing, 12, (2012), 1, pp. 320-332.

[34] Eke, İ., et al., Yapay Arı Kolonisi Algoritması Tabanlı Kararlı Güç Sistemi Dengeleyicisi Tasarımı. Gazi Üniversitesi Mühendislik-Mimarlık Fakültesi Dergisi, 26, (2011), 3.

[35] Korani, W.M., et al., Bacterial Foraging Oriented by Particle Swarm Optimization Strategy for PID Tuning. Ieee International Symposium on Computational Intelligence in Robotics and Automation, (2009), pp. 445-450.

[36] Ali, E.S., et al., Bacteria foraging optimization algorithm based load frequency controller for interconnected power system. International Journal of Electrical Power \& Energy Systems, 33, (2011), 3, pp. 633-638.

[37] Saikia, L.C., et al., Automatic generation control of a multi area hydrothermal system using reinforced learning neural network controller. International Journal of Electrical Power and Energy Systems, 33, (2011), 4, pp. 1101-1108.

[38] Dorigo, M., et al., The ant system: An autocatalytic optimizing process. TR91-016, Politecnico di Milano, (1991), pp. 1-21.

[39] Öztürk, D., et al., Calculation of surface leakage currents on high voltage insulators by ant colony algorithm-supported FEM. TURKISH JOURNAL OF ELECTRICAL ENGINEERING \& COMPUTER SCIENCES, 23, (2015), pp. 1009-1024.

[40] Mirjalili, S., et al., Grey Wolf Optimizer. Advances in Engineering Software, 69, (2014), pp. 46-61.

[41] Vila, C., et al., Mitochondrial DNA phylogeography and population history of the grey wolf Canis lupus. Molecular Ecology, 8, (1999), pp. 2089-2103. 
Vol 2, Number 1, 2017

ISSN: 2548-0332

doi: 10.23884/IJESG.2017.2.1.01

[42] Özdemir, M.T., et al., Optimal Load frequency control in two area power systems with Optics Inspired Optimization. Firat Universitesi Muhendislik Bilimleri Dergisi, 2, (2016), 28, pp. 5766.

[43] Husseinzadeh Kashan, A., A new metaheuristic for optimization: Optics inspired optimization (OIO). Computers and Operations Research, 55, (2014), pp. 99-125. 